Material Science and Engineering with Advanced Research

\title{
Failure Mode Discrimination in Mode II Fracture of Glass/Epoxy Laminates Using Acoustic Emission Technique
}

\author{
S Sajith ${ }^{1}$, V Arumugam ${ }^{1}$ and C Santulli2* \\ ${ }^{1}$ Department of Aerospace Engineering, Anna University, Chennai, India \\ ${ }^{2}$ School of Architecture and Design, Università degli Studi di Camerino, Ascoli Piceno, Italy
}

\begin{abstract}
*Corresponding author: Carlo Santulli, Professore Associato di Scienza e Tecnologia dei Materiali, Università degli Studi di Camerino, Viale della rimembranza, 63100 Ascoli Piceno, Italy, Tel: +39-0737-404282/334-1737527; E-mail: carlo.santulli@unicam.it
\end{abstract}

Article Type: Research, Submission Date: 29 July 2015, Accepted Date: 17 August 2015, Published Date: 31 August 2015.

Citation: S Sajith, V Arumugam and C Santulli (2015) Failure Mode Discrimination in Mode II Fracture of Glass/Epoxy Laminates Using Acoustic Emission Technique. Mater. Sci. Eng. Adv. Res 1(2): 16-25. doi: https://doi.org/10.24218/msear.2015.09.

Copyright: @ 2015 Carlo Santulli, et al. This is an open-access article distributed under the terms of the Creative Commons Attribution License, which permits unrestricted use, distribution, and reproduction in any medium, provided the original author and source are credited.

\begin{abstract}
The intention of this work is to discriminate the failure modes in Mode II fracture of glass/epoxy laminates on the basis of the frequency of the elastic waves emitted when the material is strained. Failure investigation was performed on end notched flexure (ENF) samples prepared with a Teflon insert in the midsection to act as delamination initiator, by performing acoustic emission (AE) monitoring on four-layer glass/epoxy laminates with different fibre stacking sequences, namely [0/0/0/0], $[0 / 90 / 90 / 0],[+45 /-45 /+45 /-45],[0 /+45 /-45 / 90]$ and $[90 /+45 /-$ $45 / 0]$. Unidirectional $[0 / 0 / 0 / 0]$ and $[0 / 0]$ laminates were also prepared as lap jointed samples and tested in shear. Moreover, pure epoxy resin specimens were tested in tensile and flexural loading to compare with composite laminates. AE monitoring by the analysis of mode II fracture was able to discriminate all the failure modes, including matrix cracks (longitudinal and transverse), interface failures, fibre micro-buckling and fibre fracture by the measurement of the different primary frequency ranges of AE signals. Considerations on the influence of fibre stacking sequence on the severity of particular failures and on the sequence of events over time leading to failure were also reported.
\end{abstract}

\section{Introduction}

Composite materials find their way from highly expensive aerospace industries to automobiles, boats, pipes and now even in our daily life due to technological improvements. Different types of matrix and reinforcing materials are in use, of which thermosets, such as epoxy, reinforced with glass or carbon fibres still particularly attract the industrial sector because of their high strength and stiffness to weight ratios. However, alongside the aforementioned advantages, composites are prone to delamination failure. Hence the investigation of the delamination damage behaviour and the knowledge of critical strain energy release rate values are of great importance [1]. Arumugam et al. have detailed the failure modes in Mode I fracture of DCB in GFRP laminates based on the frequency content of various failure modes [2]. Ramirez-Jimenez et al. have identified the failure modes in glass polypropylene composites by clustering $\mathrm{AE}$ events using frequency method [3]. AE waveform parameters are used to investigate physical damage of the composite [4-8]. Oskouei et al. used wavelet based signal processing technique to detect the damage types during Mode I fracture of glass/polyester composites [9-10]. Aggelis et al. suggested that qualitative characteristics of the signals like the shape of the waveform would provide information on the type of cracks. For example, shear cracks which normally occur during tensile fracture, emit signals with longer rise time as well as lower average frequency [11]. Chen et al. showed that in flexure of unidirectional glass fibre-reinforced composites bending strength is dominated by composite shear strength and fibre/matrix adhesion [12]. Ireman et al. conducted delamination fracture experiments on double cantilever beam (DCB), end notch flexure (ENF), mixed mode bending (MMB), crack lap shear (CLS), single edge notch (SEN) with embedded artificial delaminations or impact damages and analysed energy release rate, stress-based failure criteria and damage models [13]. Kempf et al. analysed the influence of fibre orientation, the effect of fibre-matrix adhesion and resin fracture toughness on damage initiation and propagation [14]. Unnthorsson et al. presented an AE based failure criterion equivalent to the stiffness based criterion and endurance limit in fatigue [15]. Sung-Choong Woo et al. suggested that the direction of the main crack propagation in SEN laminated composites is affected by the fiber orientation and is irrespective of the initial notch direction [16]. Liu at al. studied the influence of different layup and hole sizes on the acoustic emission and the related failure properties with the acoustic emission signal features such as the energy, counting and amplitude [17]. Qing-Qing Ni et al. proved that the frequencies of AE signals remain unchanged irrespective of the propagation distance and suggested that the combined use 
of Fast Fourier Transform (FFT) and wavelet transform (WT) could be a powerful tool for discriminating micro-failures and for elucidating the fracture mechanisms [18]. Cluster analysis is often used to discriminate various damage mechanisms [19]. In particular, Kordatos et al. analysed the relation between the fatigue limit of a ceramic matrix composite and acoustic emission data [20]. Investigation was done on the $\mathrm{AE}$ wave propagation and velocity in glass/epoxy composite materials to aid in the damage spot identification on the specimens. The results were compared with visually observed cracks and error was reduced as much as possible on the basis of the amplitude correction [21].

In the present work, delaminations are artificially induced by using Teflon inserts between the layers, so that mode II delamination test is carried out on laminates with different fibre stacking sequences using acoustic emission monitoring. Different types of failure modes are discriminated based on the frequency of the signals that are emitted during subsequent stages of loading and the dependence of certain failure modes on the orientation of fibre in the stacking sequence. The resistance offered at the interface of different fibre orientation is related to the absolute energy of acoustic emission signals and the number of events related to the interface failures and thus dependence of interlaminar fracture strength on fibre orientation is elucidated.

\section{Materials and Methods}

\section{Materials}

Unidirectional E-glass fibre cloth with mass density $270 \mathrm{~g} / \mathrm{m}^{2}$ is used as the reinforcing phase in the composite laminates, where epoxy Araldite resin (LY556) and hardener (HY951) formed the matrix phase. Fibre and epoxy were taken in equal mass proportion and amount of hardener taken is $10 \%$ by mass of epoxy resin, so that in the end glass fibre content was $47.5 \pm 0.5$ wt.\%. Hardener is added to epoxy and stirred well. Four-layered $300 \times 300 \mathrm{~mm}$ GFRP composite laminates with fibre stacking sequences $[0 / 0 / 0 / 0],[0 / 90 / 90 / 0],[+45 /-45 /+45 /-45],[0 /+45 /-$ $45 / 90]$ and $[90 /+45 /-45 / 0]$ were fabricated by compression moulding technique. A non-adhesive insert (Teflon) of thickness of $13 \pm 1$ microns was inserted in the mid-plane to serve as delamination initiator. The laminates were cured at room temperature for 24 hours. End notch flexure (ENF) specimens with dimensions $130 \times 25 \times 5$ were cut from each laminate using water jet cutting process. On the edge of each specimen, a Teflon insert of length $30 \mathrm{~mm}$ and width $25 \mathrm{~mm}$ was disposed, as shown in Figure 1a.

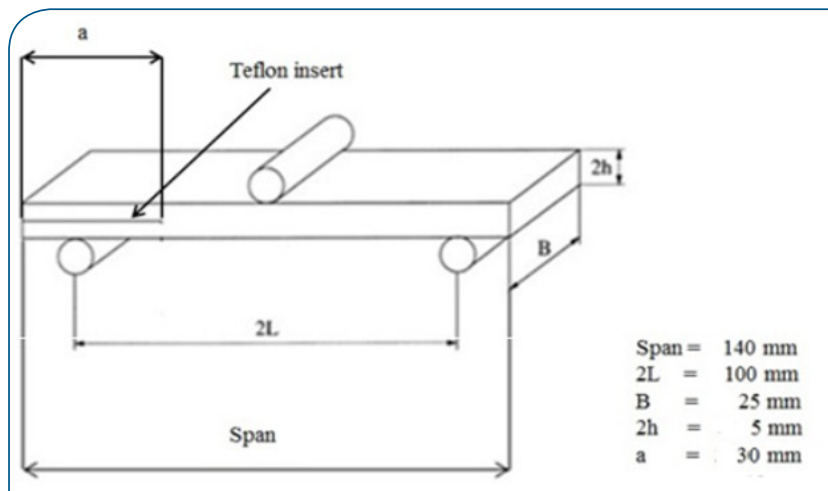

\section{Three-point flexural testing and tensile testing of pure resin samples}

Pure epoxy resin specimens were prepared with dimensions $140 \times 12.5 \times 5 \mathrm{~mm}$ and were subjected to flexural loading through three-point fixture with a support span of $100 \mathrm{~mm}$ using a Tinius Olsen H100KU universal testing machine, with a $100 \mathrm{kN}$ load cell. Tensile testing was carried out on pure epoxy resin specimens of dimensions $260 \times 25 \times 5$ through tensile fixture with a gage length of $160 \mathrm{~mm}$ and $50 \mathrm{~mm}$ was given for gripping on both sides. Five samples were tested for each loading mode (flexural or tensile). Displacement control mode was applied throughout all testing. The crosshead speed was maintained at a rate of $1 \mathrm{~mm} / \mathrm{min}$ for three-point bending and $0.5 \mathrm{~mm} / \mathrm{min}$ for tensile testing.

\section{Testing on GFRP laminates}

Mode II delamination testing: In Mode II delamination test the specimens are subjected to bending load in transverse direction using Tinius Olsen H100KU Universal Testing Machine, with a $100 \mathrm{kN}$ load cell as in Figure 1b. Five specimens per each stacking sequence were tested. Displacement control mode of testing is preferred as per ASTM D5528-01. The crosshead speed was maintained at a rate of $1 \mathrm{~mm} / \mathrm{min}$. Crack initiation was identified by tracing marks at the side of the specimen. The loading is similar to simply supported beam with concentrated load at the centre. Teflon insert is at the neutral layer and the layers above the insert are subjected to compression and the layers below are subjected to tension. Shear force is maximal at the neutral layer. Due to this shear force sliding of the layers above and below the neutral layer occurs, which results in delamination.

Lap shear testing: Shear test was carried out on two types of laminates, in a number of five for each type. The first type consisted of single lap jointed unidirectional GFRP, as shown in Figure 2a, with a thick layer of epoxy resin entrapped at the joint. The fact that the laminate has a resin-rich area at the interface would suggest that its dominant failure mode is cohesive shear fracture rather than fibre/matrix debonding. The second type consisted of four-layered unidirectional GFRP laminates, as shown in Figure $2 \mathrm{~b}$ were fabricated using compression moulding. These are single piece laminates with two notches and no external joint. In this case, a thin layer of epoxy is present at the interface, so to imply that fibre/matrix debonding would rather be dominant over cohesive shear fracture. These tests give the combined debonding and cohesive shear fracture strength of the laminate. In both cases, the load is carried by the small

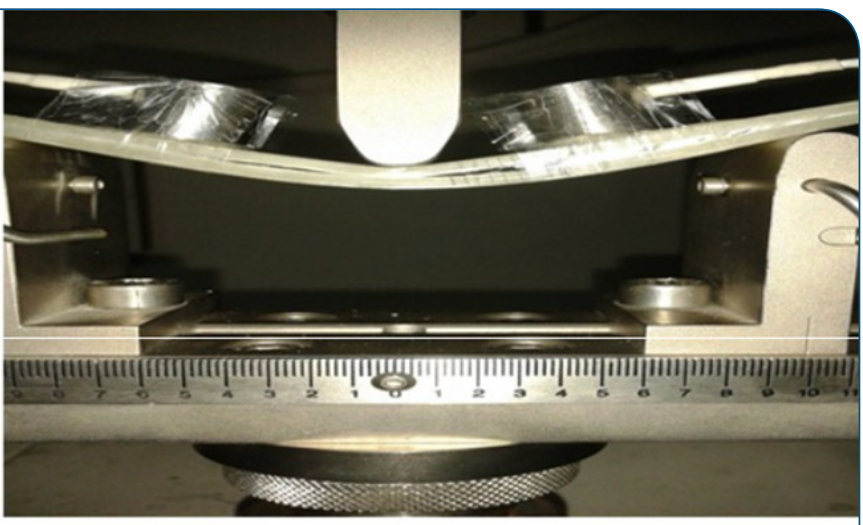

(b) 


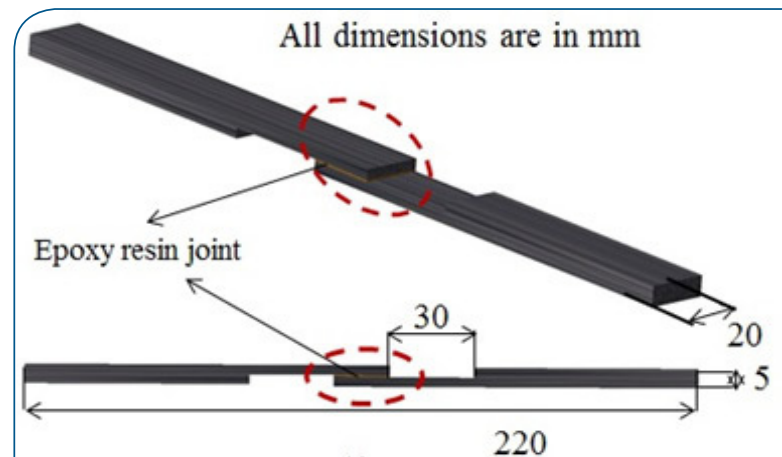

(a)

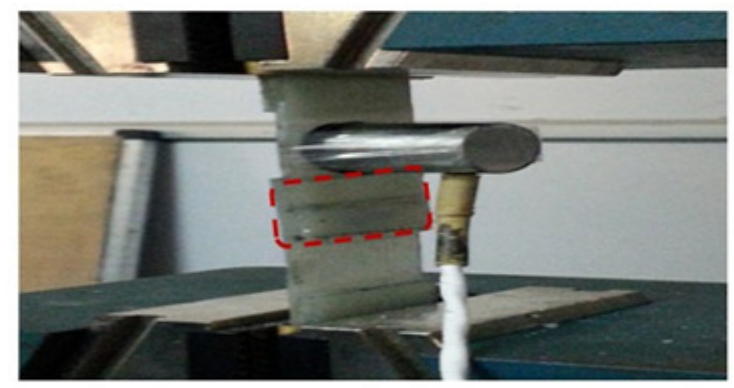

(c)

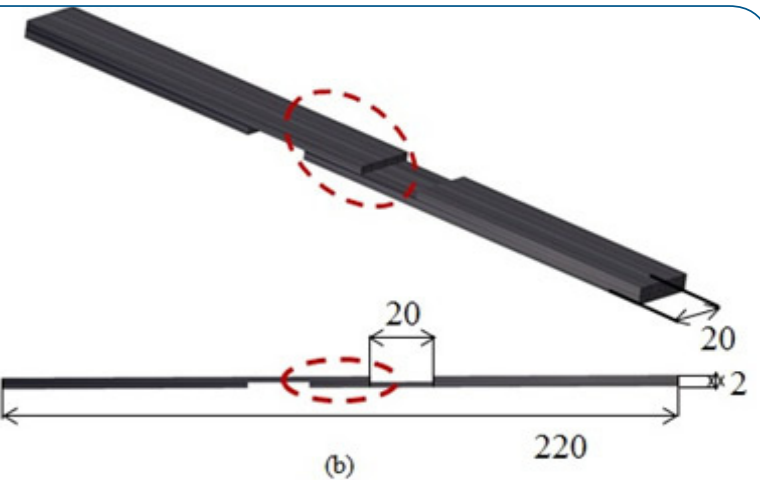

(b)

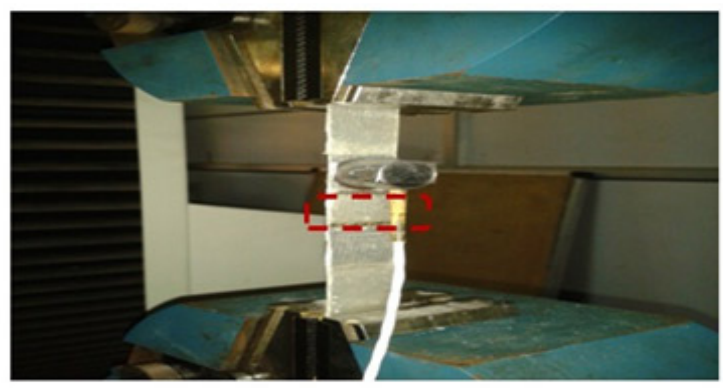

(d)

Figure 2: Shear tests of two-layer lap jointed unidirectional GFRP: a. Dimensions; c. Testing procedure Shear tests of fourlayer notched unidirectional GFRP: b. Dimensions; $d$. Testing procedure

area rounded in Figure 2c and Figure 2d. Two acoustic emission sensors were applied on the specimens at a mutual distance of $80 \mathrm{~mm}$. Tensile load was applied using Tinius Olsen H100KU universal testing machine, with a $100 \mathrm{kN}$ load cell. The gage length was maintained as $140 \mathrm{~mm}$ and $40 \mathrm{~mm}$ was given for gripping. Load was applied in displacement control mode, with a crosshead speed of $0.5 \mathrm{~mm} / \mathrm{min}$.

\section{Acoustic emission (AE) monitoring}

An eight channel AE system, supplied by Physical Acoustics Corporation (PAC), was used for the continuous monitoring of AE data, carried out specifically with a SAMOS E3.10 data acquisition system, again from PAC, with a sampling rate of 3 mega-samples per second (MSPS) and a $40 \mathrm{~dB}$ pre-amplification. The amplitude distribution covers the range of $0-100 \mathrm{~dB}(0 \mathrm{~dB}$ corresponds to $1 \mathrm{mV}$ at the transducer output). Ambient noise was filtered using a threshold equal to $45 \mathrm{~dB}$. On all flexural samples wideband sensors, with a quasi-flat response over the $100-900 \mathrm{kHz}$ range, were applied at a mutual distance of $80 \mathrm{~mm}$ equidistant from the centre of the sample, while on tensile samples their mutual distance was $120 \mathrm{~mm}$. In particular, attention was concentrated on the time and space localisation of the signals, on their primary frequency content and on cumulative variables accounted for during the tests, such as hits, counts and energy.

\section{Results and Discussion}

\section{AE monitoring on pure resin samples during tensile and flexural tests}

By investigating the frequencies of the signals from pure epoxy resin specimens it is clearly seen that events are exclusively concentrated in two frequency ranges: $80-130 \mathrm{kHz}$ and 240-270 $\mathrm{kHz}$, as shown in Figure $3 \mathrm{a}$ and Figure $3 \mathrm{~b}$, which are referred to flexural and tensile tests, respectively. As for the former frequency range, it has been widely recognised as primary frequencies of events related to matrix cracking in the transverse direction, for example as the effect of fibres being pulled out, are concentrated in a range centred approximately on $100 \mathrm{kHz}$ [22-23]. A closer observation of the results on pure matrix samples, considering also the energy values of the respective events, as in Figure $3 \mathrm{c}$ and $3 \mathrm{~d}$, for flexural and tensile loading, respectively, does clarify that in both cases higher energy values are revelaed in the case of some $240-270 \mathrm{kHz}$ events, with higher evidence in the case of tensile loading. It can be suggested that the absolute energy of matrix microcrack in the length direction is higher than the matrix transverse crack, which is also true for cracks originating in the tensile region of the flexural sample. So the failure modes occurring on pure matrix samples are identified as matrix micro crack in specimen length direction due to tension with frequency $240-270 \mathrm{kHz}$ and matrix transverse crack with frequency 80-130 $\mathrm{kHz}$ in thickness direction.

The comparative analysis of the two matrix fracture modes has also been carried out on the different GFRP laminates produced, where obviously also other failure modes were present, as detailed further later. Figure 4 shows the ratio between matrix microcracks, for which signals in the $240-270 \mathrm{kHz}$ range are detected, and matrix transverse cracks, which give rise instead to signals in the $80-130 \mathrm{kHz}$ range, in glass fibre reinforced epoxy laminates with different fibre stacking sequence during ENF testing. It can be clearly seen that in all the laminates the occurrence of $80-130 \mathrm{kHz}$ signals is lower compared to those in the $240-270$ $\mathrm{kHz}$ range. it can be suggested that the presence of glass fibre in the laminate prevents the transverse cracking in the through thickness direction. This is further confirmed by the fact that laminates with 90 and 45 degree fibre orientation in the bottom layer show comparatively more matrix transverse crack because they allow crack to be propagated through the layer, which is not the case for 0 degree ply. 

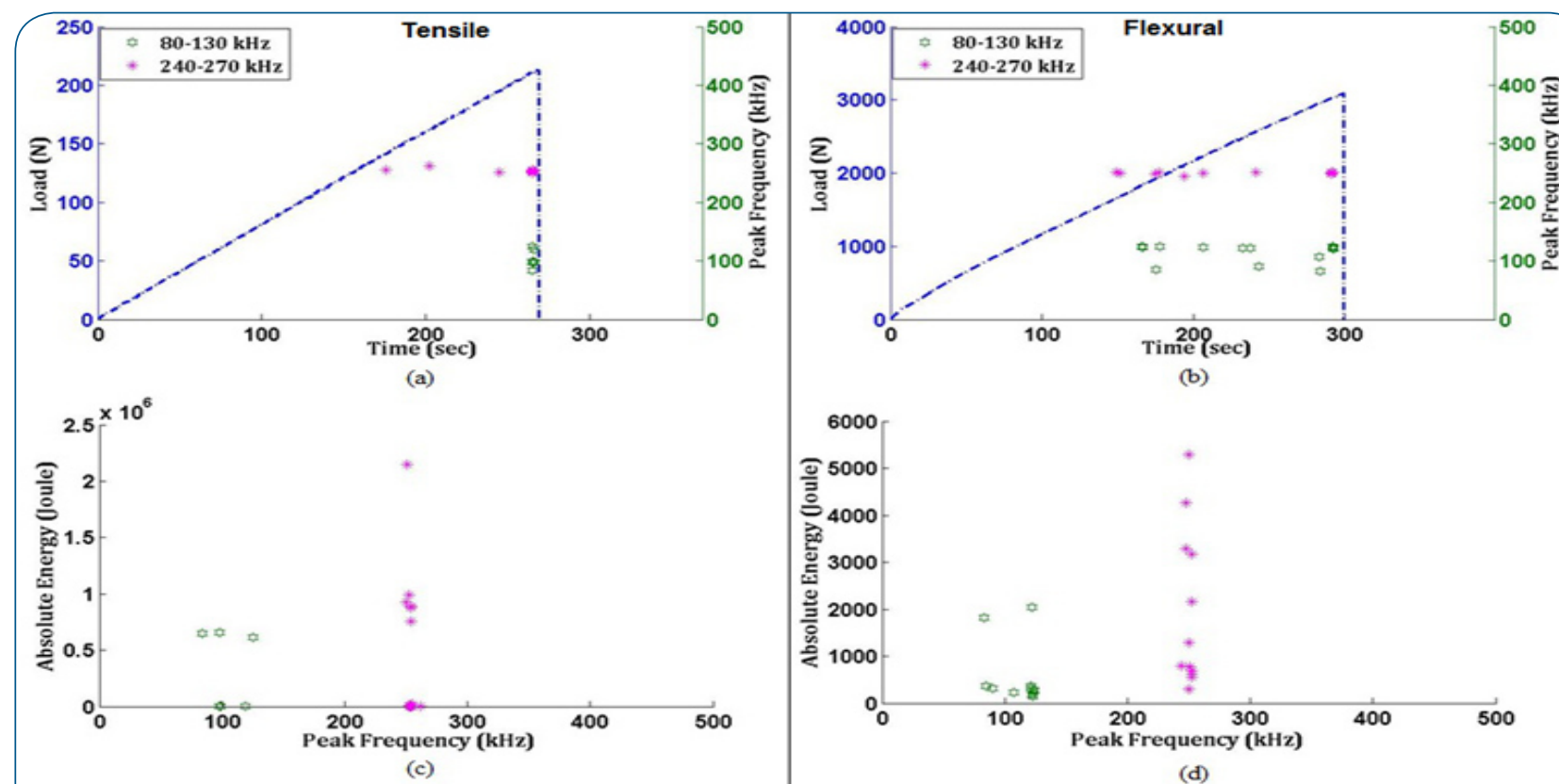

(b)

Figure 3: AE activity on pure resin samples:

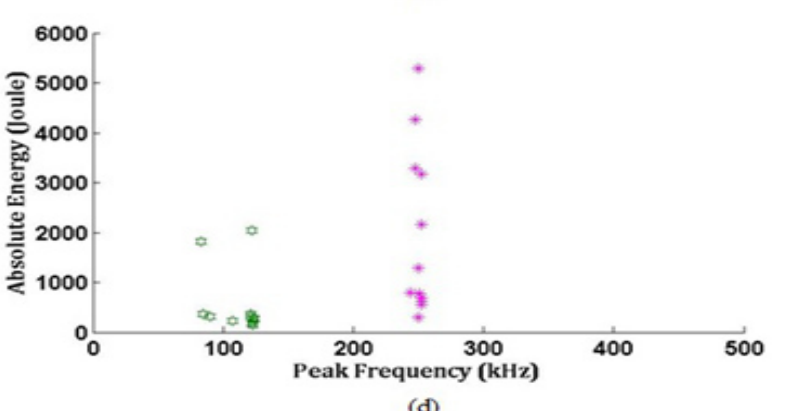

(d)

Peak frequency of AE events during: (a) Flexural loading; (b) Tensile loading;

Energy content of AE events during: (c) Flexural loading; (d) Tensile loading.

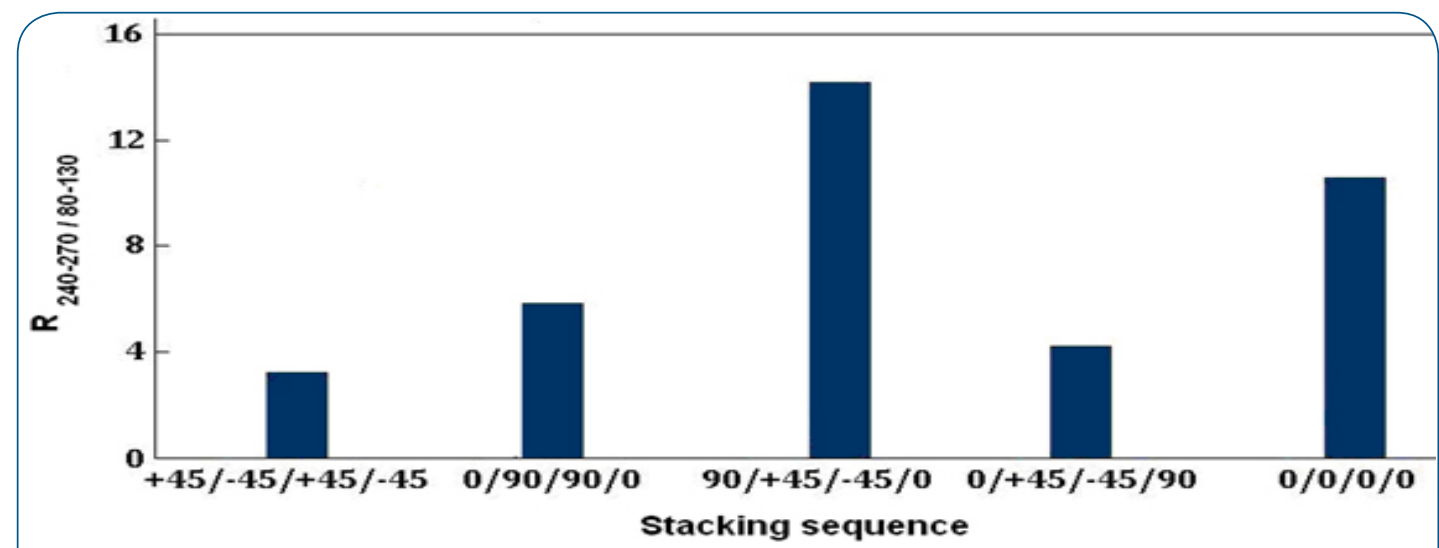

Figure 4: Ratio between events detected in the range $240-270 \mathrm{kHz}$ (likely matrix micro-cracks) and those detected in the range $80-130 \mathrm{kHz}$ (likely matrix transverse cracks)

Failure modes in elastic and plastic region of end-notch flexure (ENF) laminates undergoing fracture

In general terms, it can be observed from Table 1 as end notch flexure tests provide results that are not very different for composites with the various stacking sequences under study, although the presence of +45 and -45 layers is clearly quite detrimental for the final performance, most likely as an effect of premature transverse cracking [24]. During the initial

\begin{tabular}{|l|l|}
\hline Stacking sequence & Max. load $(\mathbf{N})$ \\
\hline $0 / 90 / 90 / 0$ & $670 \pm 25$ \\
\hline $90 /+45 /-45 / 0$ & $515 \pm 30$ \\
\hline $0 /+45 /-45 / 90$ & $550 \pm 20$ \\
\hline$+45 /-45 /+45 /-45$ & $405 \pm 25$ \\
\hline $0 / 0 / 0 / 0$ & $640 \pm 55$ \\
\hline
\end{tabular}

Table 1: Max. flexural load (N) of different composite materials stage of ENF samples loading, a clear proportionality between load and displacement can be observed. The departure from proportionality is typically indicated by an abrupt increase in $\mathrm{AE}$ cumulative energy, as can be observed in Figure 5. In particular, remaining $\mathrm{AE}$ events are divided in three further frequency ranges, in particular $140-190 \mathrm{kHz}, 275-295 \mathrm{kHz}$ and $300-320$ $\mathrm{kHz}$. When the shear stress in the interface crosses the critical limit rapid failure occurs along with large number of failure events and abrupt hike in absolute energy.

\section{Frequency distribution of ENF laminates under Mode II loading}

It is interesting to note that ENF laminates undergoing mode II loading present characteristic and repeatable AE activity as regards the frequency distribution of the events, which can be divided into five ranges, namely $80-130 \mathrm{kHz}, 140-190 \mathrm{kHz}, 240$ $270 \mathrm{kHz}, 275-295 \mathrm{kHz}$ and $300-320 \mathrm{kHz}$, the first and third of these, as from Section 3.1, do refer to longitudinal and transverse 


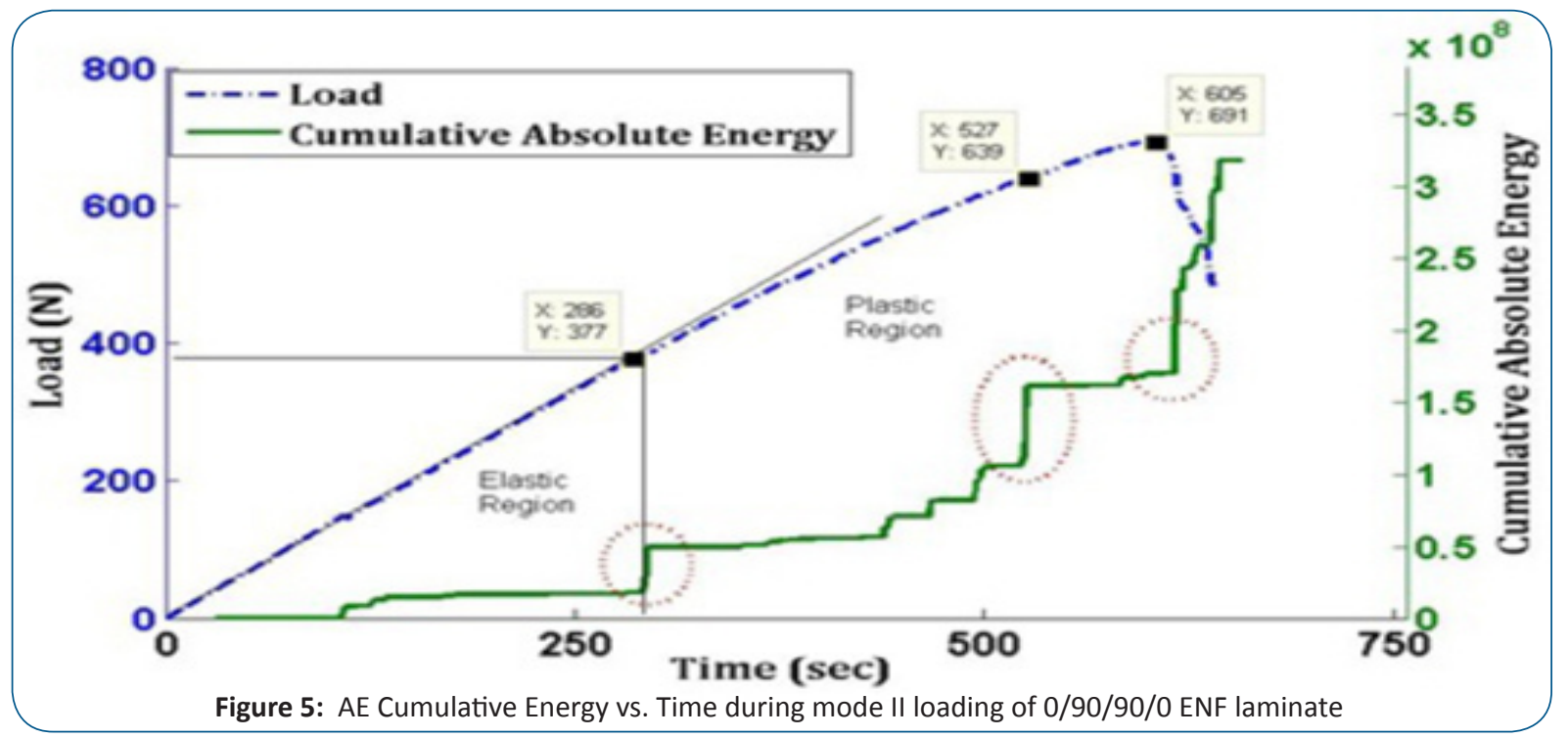

matrix cracking, respectively. As from data reported in Figure 6 , within the proportional limit the material undergoes elastic strain with a lower number of matrix crack events occurring near the proportional limit. As far as the plastic region is concerned initial stages are dominated by matrix cracking failures and then in course of time accompanied by other failures. The other three frequency ranges will be identified via the considerations developed in the following sections.

\section{Identification of fibre micro-buckling mode}

The occurrence of fibre micro-buckling has been recognised as the effect of shear instability in fiberglass, which is very detrimental for its performance under out-of-plane loading [25]. This is likely to occur on the compressed side of the laminate, hence is influenced by fibre orientation of top layers. In mode II loading, the likeliness of fibres in the top layers to buckle would strongly depend on stacking sequence: in practice, with 0 and 45
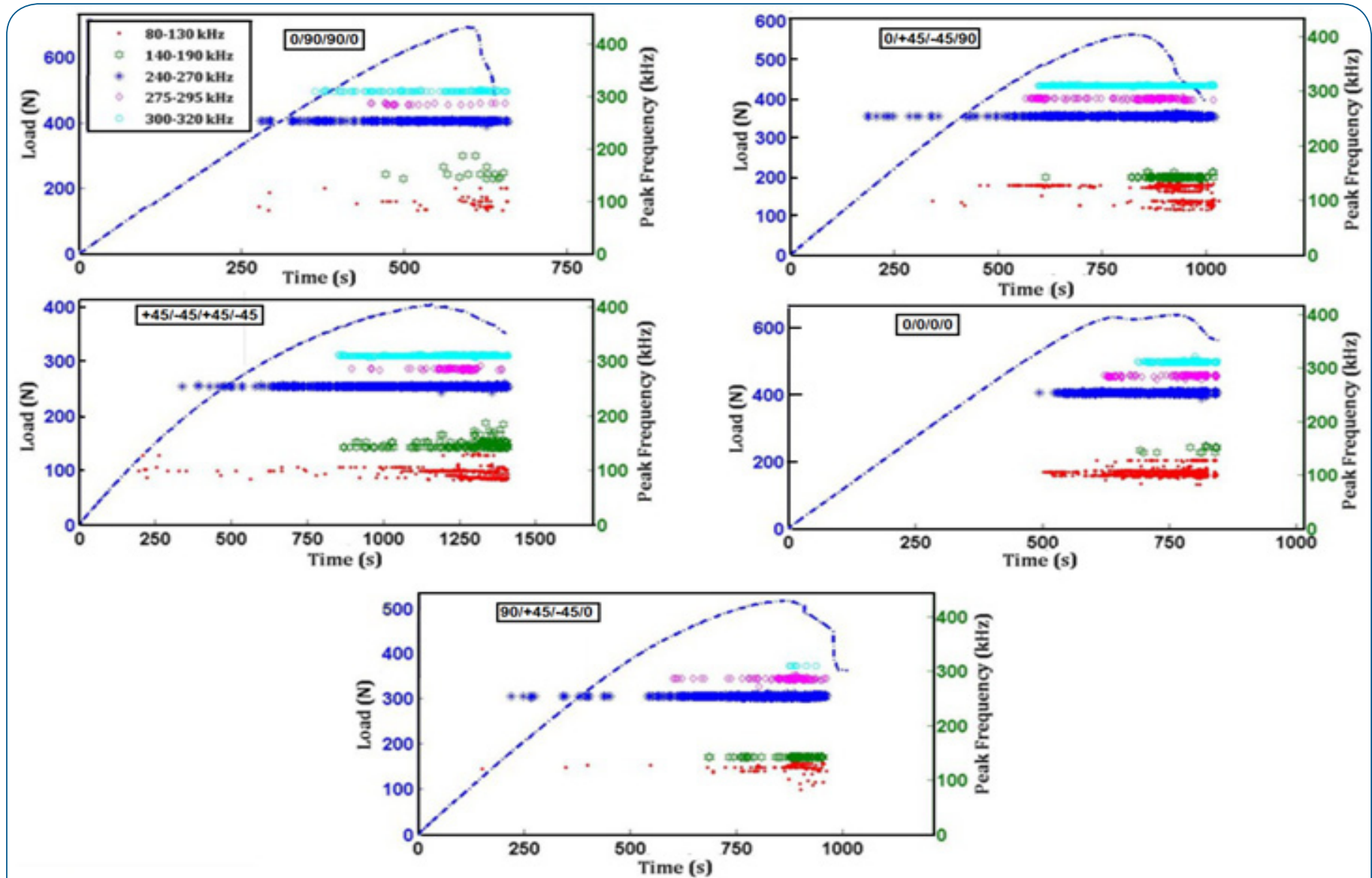

Figure 6: Load vs. Time with AE Peak frequency of laminates with different fibre stacking sequences under Mode II Loading 
degree ply on top buckling will be higher and with 90 degree on top buckling is very much unlikely to occur. It has been noticed that $\mathrm{AE}$ events with frequency range between 300 and $320 \mathrm{kHz}$, although found in all laminates, have an occurrence that variess considerably with different fibre stacking sequences. The number of $\mathrm{AE}$ events with primary frequency in the range between 300 and $320 \mathrm{kHz}$ in various laminates with different fibre stacking sequences is shown in Figure 7. There is a very significant difference in the number of fevents between $0 /+45 /-45 / 90$ and $90 /+45 /-45 / 0$ laminates, in which the top layers are 0 and 90 degree ply, respectively. Therefore this range, often associated with fibre failure, also in studies on carbon fibre composites [26], might be correlated to a considerable extent to breakage occurring as an effect of fibre micro-buckling.
A further confirmation of this comes from AE frequency distribution in lap shear testing of GFRP laminates, which is shown in Figure 8 . The $300-320 \mathrm{kHz}$ frequency range, which is available in Mode II fracture of ENF is missing in this case, whereas here frequency range between 350 and $380 \mathrm{kHz}$ is present in shear testing. Under tension load there are no possibilities for fibre to buckle and that is why $300-320 \mathrm{kHz}$ did not occur in shear test, while in contrast the fibre could break under tension load. Moreover, it was described already in [2] that frequency range $350-380 \mathrm{kHz}$ might be related to fibre breakage, hence 300 $320 \mathrm{kHz}$ is to be ascribed to micro-buckling.

\section{Discrimination of interface failures}

Interface failures may obviously occur only if there is more

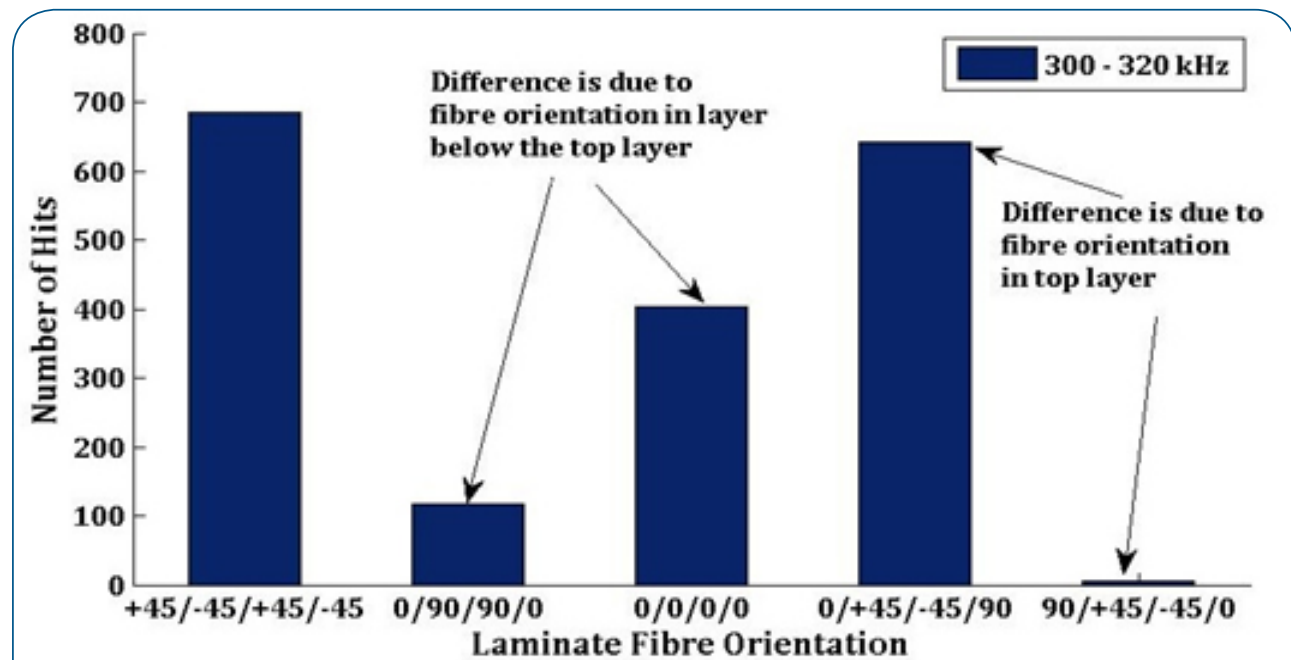

Figure 7: Comparison of number of hits with frequency in the range between 300 and $320 \mathrm{kHz}$ failure mode in GFRP laminates with different fibre stacking sequences under ENF test

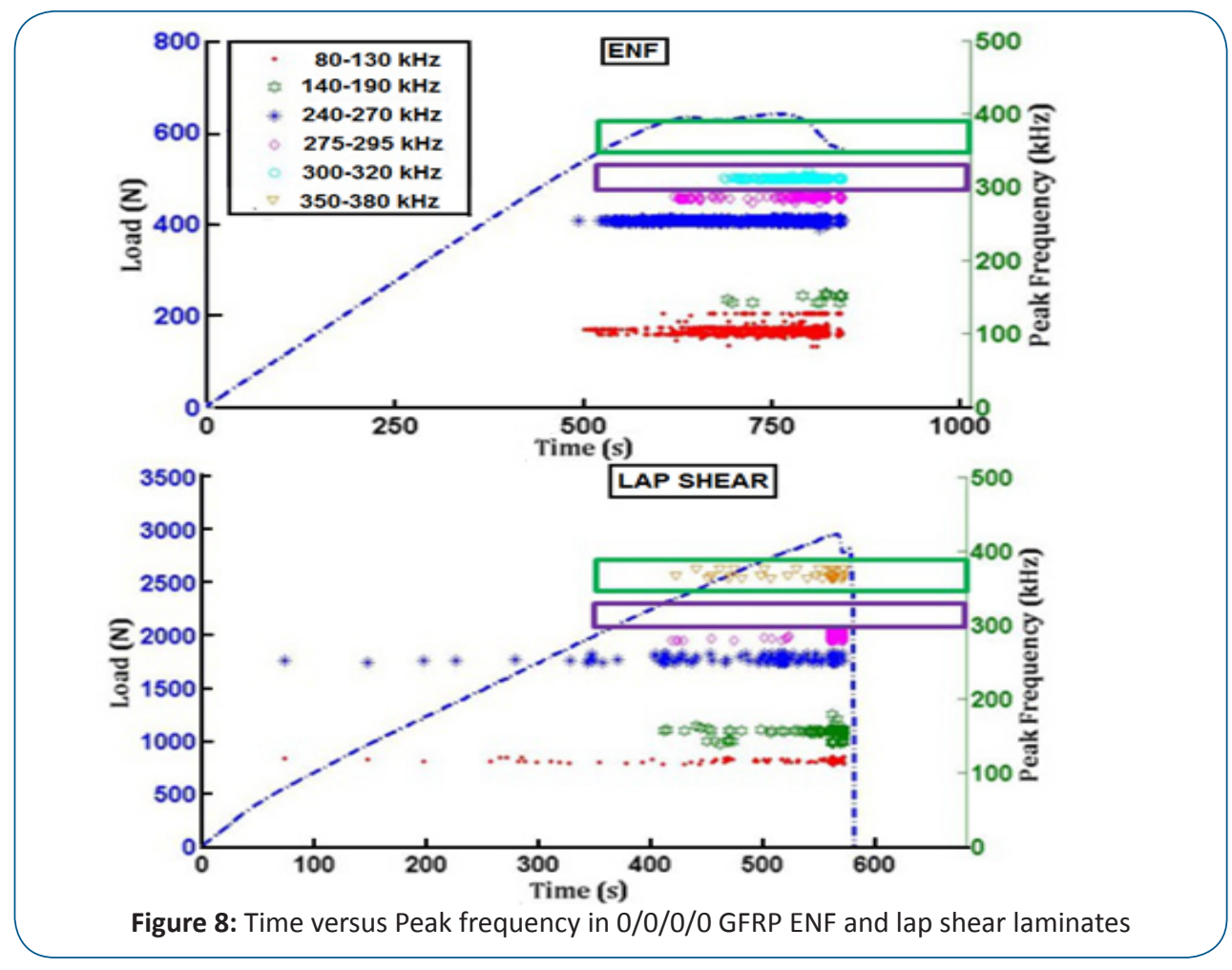


than one layer. AE events detected in both shear and mode II delamination testing of ENF GFRP laminates, have frequencies in two further frequency ranges, $140-190 \mathrm{kHz}$ and $275-295 \mathrm{kHz}$ : however, events in these frequency ranges were not detected during flexural loading of pure resin laminates. So these frequency ranges might be likely related to interface failures, in particular fibre/matrix debonding and cohesive shear fracture. The distribution of frequency content of events at different location of ENF specimen under Mode II loading is shown in Figure 9.

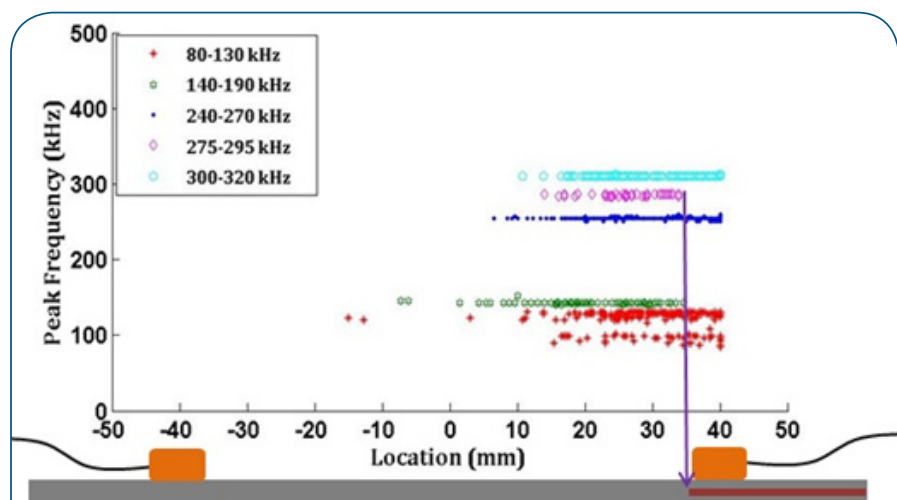

Figure 9: Location versus Peak frequency in AE events detected during testing of a ENF laminate

It can be seen that events in the frequency ranges $140-190 \mathrm{kHz}$ and $275-295 \mathrm{kHz}$ are not present in the region where Teflon is inserted as delamination initiator in the interface, even though it is within the field of acoustic emission sensor. This suggests that those frequencies might be related to interface failures fibre/ matrix debonding and cohesive shear fracture. Since in this region the interface is already separated, there is no possibility of interface failures. In [2], it was detailed that failure modes occurring in Mode I delamination i.e., fibre/matrix debonding and fibre pullout failure are most likely to occur in $150-240 \mathrm{kHz}$ frequency range.

The view of failed interface of resin rich lap jointed GFRP specimen and resin lean GFRP shear specimen are shown in Figure 10. It can be seen from Figure 10b that in resin lean shear specimen a lot of fibre is exposed than in resin rich lap jointed specimen in Figure 10a. This is due to the fact that in resin lean shear specimen the fracture crack propagates through the fibrematrix interface leaving the fibre exposed. But in resin rich lap jointed specimen the fracture crack propagates mostly through the matrix that trapped between the interface layers which is why no fibre is exposed to the surface. So if comparison is done on the number of failures between $140-190 \mathrm{kHz}$ and $275-295 \mathrm{kHz}$ it might give clear information.

The number of AE events with primary frequency in the ranges $140-190 \mathrm{kHz}$ and $275-295 \mathrm{kHz}$ in resin lean shear specimen of GFRP laminates and resin rich lap jointed GFRP laminates is shown in Figure 11. It can be seen that in resin lean shear laminate the number of events in the frequency range 140-190 $\mathrm{kHz}$ is higher than those in the range $275-295 \mathrm{kHz}$, whereas the opposite is true in resin rich lap joints. This might happen since in lap joints cohesive shear fracture is more likely to occur than fibre/matrix debonding due to the thick layer of resin that allows the fracture crack to be propagated with-in the matrix. So events with frequency in the range between 140 and $190 \mathrm{kHz}$ might be related to fibre/matrix debonding and those in the range between 275 and $295 \mathrm{kHz}$ might be related to cohesive shear fracture. Thus, all failures that were involved in Mode II fracture are discriminated.

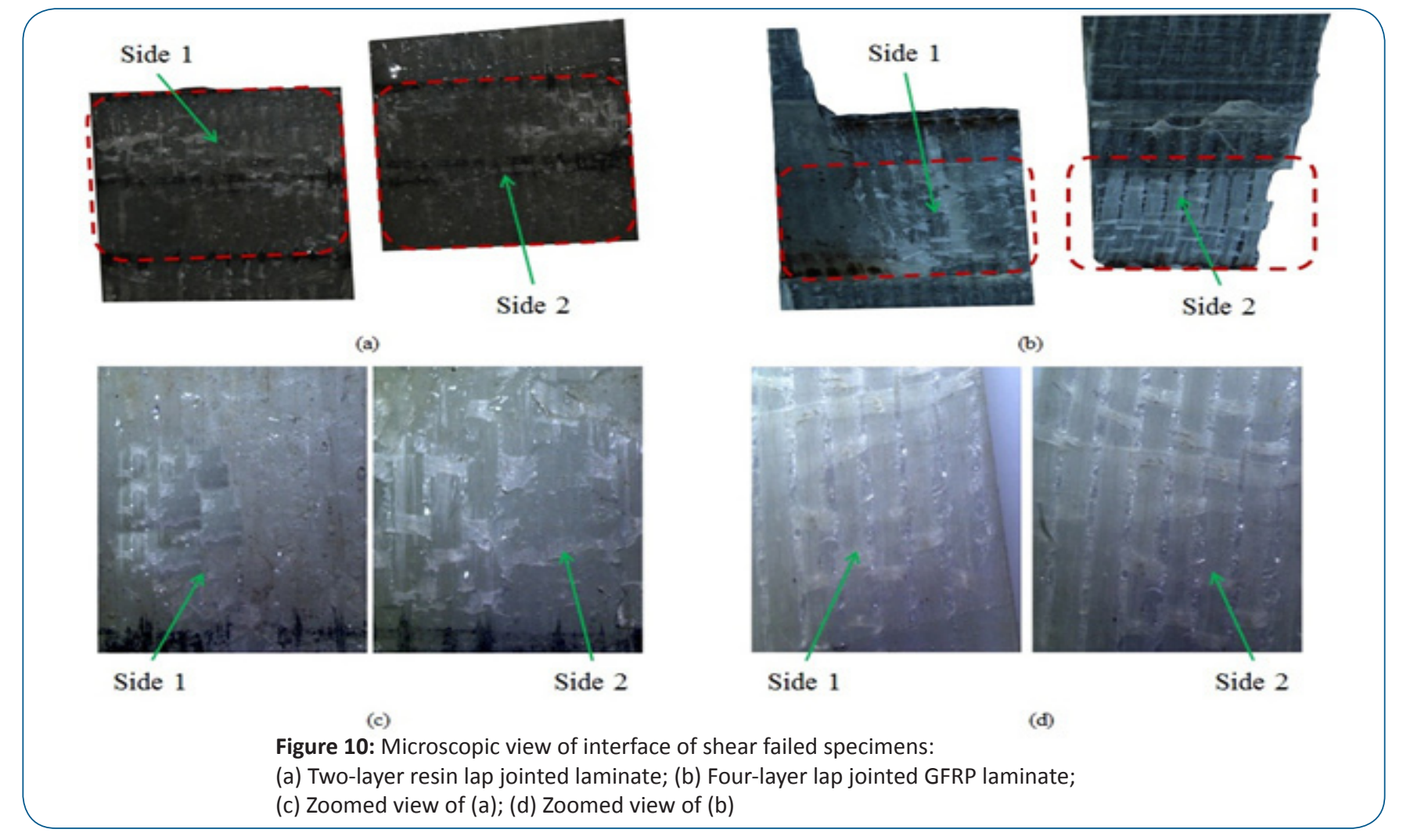

Mater. Sci. Eng. Adv. Res 1(2). 


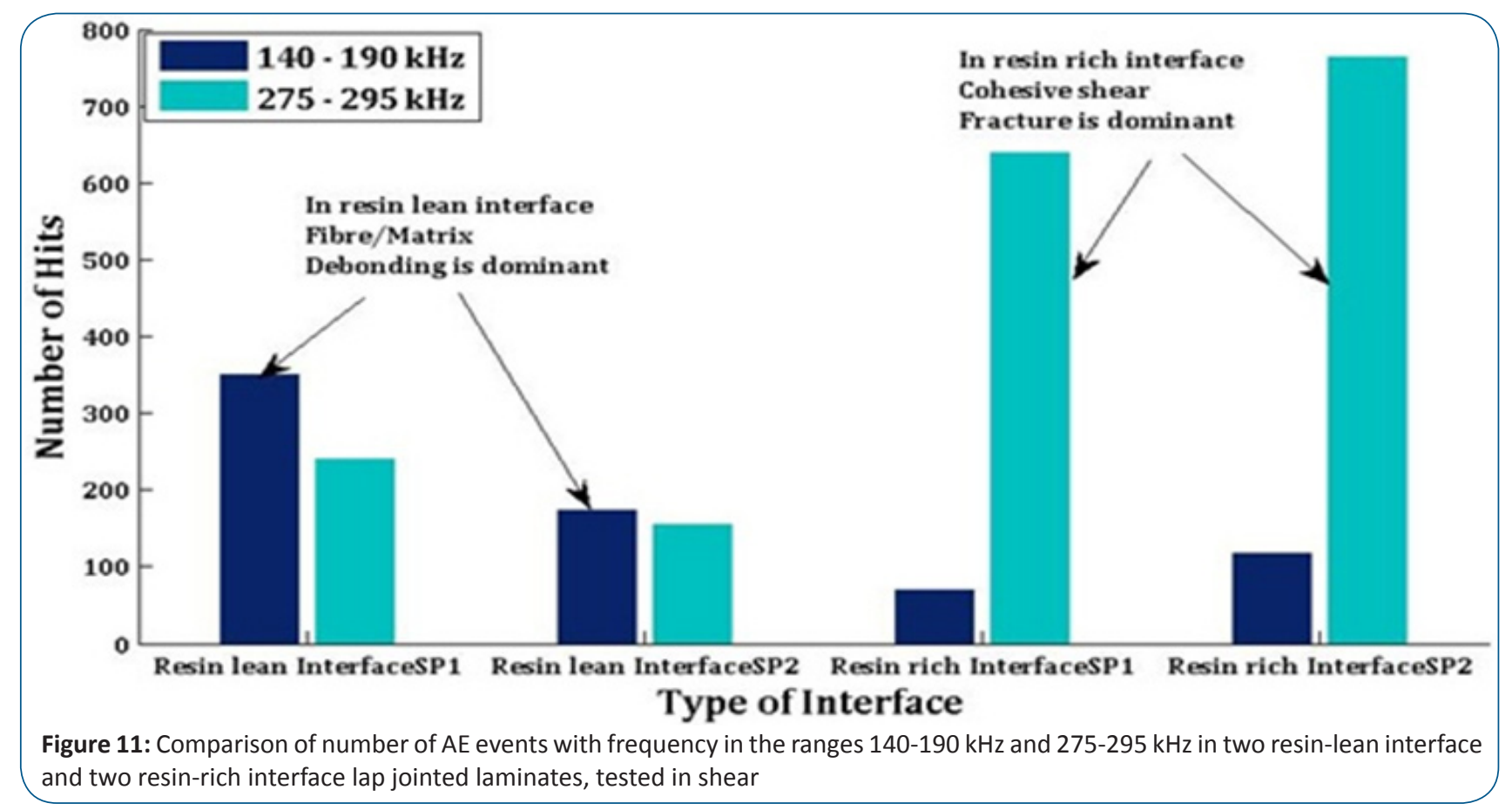

Now, the delamination resistance offered by the interfaces with different fibre orientation has to be investigated to find the best possibility of fibre orientation for better delamination resistance. The shear stress resistance in laminates with different stacking sequences are shown in Figure 12. 0/0/0/0 shows good

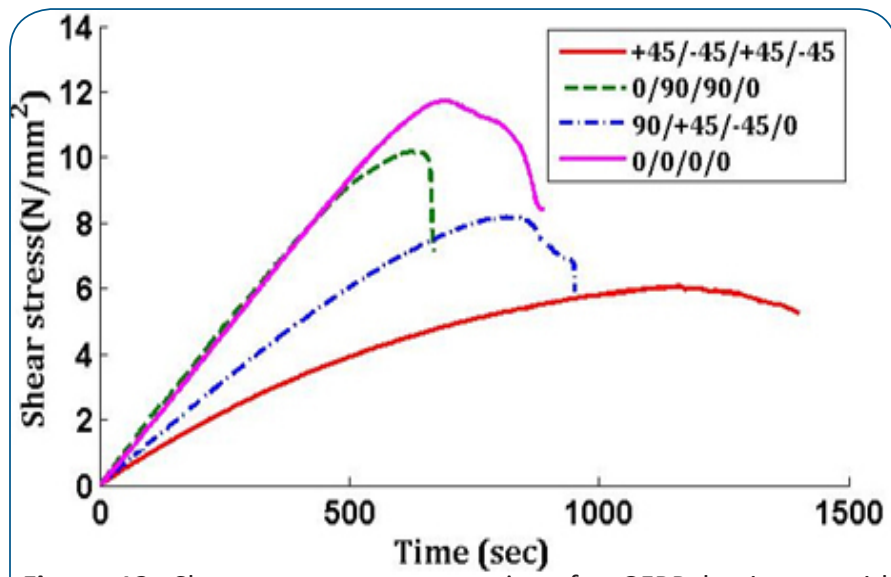

Figure 12: Shear stress curves vs. time for GFRP laminates with different fibre stacking sequence

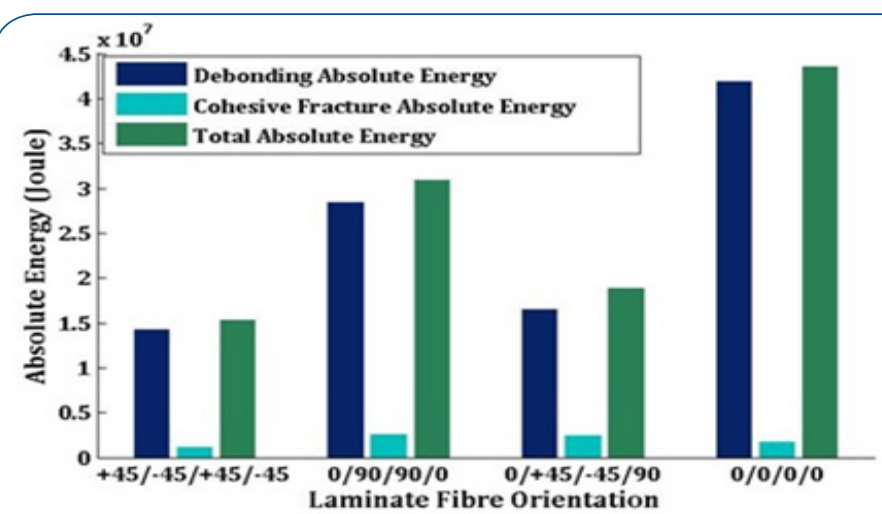

(a) shear resistance followed by $0 / 90 / 90 / 0,90 /+45 /-45 / 0$ and $+45 /-$ $45 /+45 /-45$ respectively. However, looking at the time taken for ultimate failure, $0 / 0 / 0 / 0$ and $0 / 90 / 90 / 0$ failed quite abruptly compared to other laminates. This can be attributed to the fact that displacement control mode of testing was applied and that the amount of fibres in the loading direction is substantial. In this loading mode, displacement varies linearly with time but load carried by the laminate depends on the stiffness of the laminate. $0 / 0 / 0 / 0$ is stiffer because of the four 0 degree plies and then also $0 / 90 / 90 / 0$ is rather stiff, because of the two 0 degree plies and hence they carry more load in short time and will fail quickly. Shear stress is calculated as below:

Shear stress $=\frac{F \times A \times y ́}{I \times b}$

The absolute energy of interface failures which occurred during Mode II fracture is reported in Figure 13a, showing from respective $\mathrm{AE}$ events frequencies that fibre/matrix debonding contributes much more than cohesive fracture to the delamination resistance in all laminates. In addition, $0 / 0 / 0 / 0$ laminates released more energy before failure thus offered

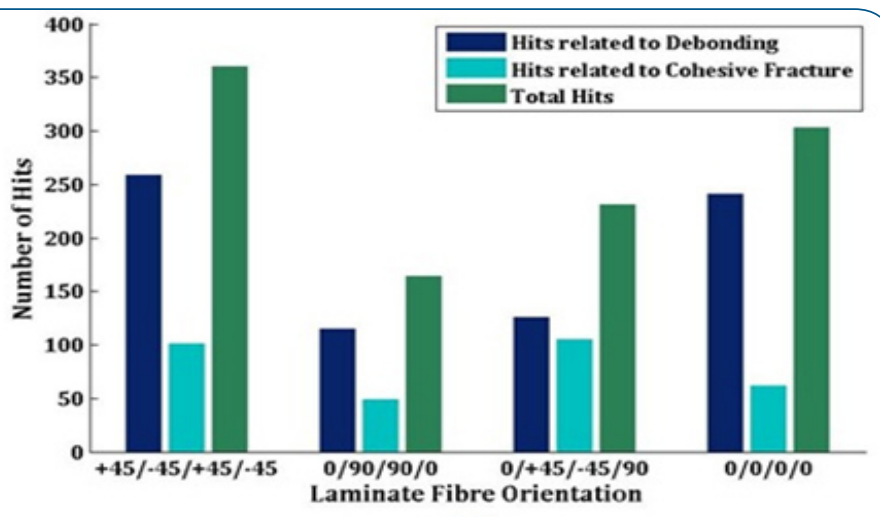

(b)

Figure 13: Comparison of: (a) AE energy and, (b) Number of events likely to be attributed to fibre/matrix debonding (140-190 kHz) and cohesive fracture $(275-295 \mathrm{kHz})$ of GFRP laminates 
Citation: S Sajith, V Arumugam and C Santulli (2015) Failure Mode Discrimination in Mode II Fracture of Glass/Epoxy Laminates Using Acoustic Emission Technique. Mater. Sci. Eng. Adv. Res 1(2): 16-25. doi: https://doi.org/10.24218/msear.2015.09.

good resistance followed by $0 / 90 / 90 / 0$. In contrast, laminates $90 /+45 /-45 / 0$ and $+45 /-45 /+45 /-45$ offered more or less the same resistance, suggesting that their interfacial strength is around the same level. In general terms, this indicated that interlaminar fracture resistance depends on the interface fibre orientation. In particular, even though $90 /+45 /-45 / 0$ and $+45 /-45 /+45 /-45$ have same fibre orientation in the middle layers, $90 /+45 /-45 / 0$ shows higher shear stress than $+45 /-45 /+45 /-45$. This is explained by the fact that 0 ply in $90 /+45 /-45 / 0$ imparts a higher rigidity to the laminate, though in general terms it leads it to precocious failure with respect to $+45 /-45 /+45 /-45$. Figure 13 b shows the number of failure events corresponding to fibre/matrix debonding and cohesive fracture in different laminates. In this case, the ultimate cumulative energy released by $90 /+45 /-45 / 0$ and $+45 /-45 /+45 /-$ 45 are nearly equal, but the number of failure events are much higher in $+45 /-45 /+45 /-45$ than in $90 /+45 /-45 / 0$. It is suggested therefore that $90 /+45 /-45 / 0$ carries more load, while collapsing more abruptly. During final fracture, a lower number of $\mathrm{AE}$ events with high energy are detected. Quite to the contrary, $+45 /-$ $45 /+45 /-45$ laminate carries a lower amount of load for a longer period of time. As a result, a large number of AE events with low energy are in contrast detected.

\section{Conclusions}

Failure events occurring during Mode II fracture of E-glass/ epoxy laminates are discriminated on the basis of the frequency content of acoustic emission events emitted during fracture. In particular, acoustic emission is seen as able to discriminate between matrix transverse and longitudinal cracks, therefore being useful to investigate the effect of stacking sequence on the relative significance of the different failure modes. In particular, for example, fibre micro-buckling failure was clearly minimised by having 90 degree plies on top layers of laminates. Also interlaminar fracture resistance was proved depending on the fibre orientation of interface layers with 0 degrees plies offering the highest interlaminar fracture resistance. More in general, interlaminar fracture resistance is offered by the combined contribution of bonding between fibre-matrix interface and cohesive strength of the matrix.

\section{References}

1. ASTM D5528-01: Standard test method for mode I interlaminar fracture toughness of unidirectional fiber-reinforced polymer matrix composites. Annual Book of ASTM Standard. 2004; 15.03

2. Arumugam V, Sajith S, Joseph Stanley A. Acoustic Emission Characterization of Failure Modes in GFRP Laminates Under Mode I Delamination. Journal of Nondestructive Evaluation. 2011; 30(3):213-219. doi: 10.1007/s10921-011-0109-5.

3. Ramirez-Jimenez CR, Papadakis N, Reynolds N, Gan TH, Purnell PM. Identification of failure modes in glass/polypropylene composites by means of the primary frequency content of the acoustic emission event. Composites Science and Technology. 2004; 64(12):18191827. doi:10.1016/j.compscitech.2004.01.008.

4. Mili M, Moevus M, Godin N. Statistical fracture of E-glass fibres using a bundle tensile test and acoustic emission monitoring. Composites Science and Technology. 2008; 68(7-8): 1800-1808. doi:10.1016/j.compscitech.2008.01.018.
5. Kostopoulos V, Tsotra P, Karapappas P, Tsantzalis S, Vavouliotis A, Loutas TH, et al. Mode I interlaminar fracture of CNF or/and PZT doped CFRPs via acoustic emission monitoring. Composites Science and Technology. 2007; 67(5):822-828. doi:10.1016/j. compscitech.2006.02.038.

6. Huguet S, Godin N, Gaertner R, Salmon L, Villiard D. Use of acoustic emission to identify damage modes in glass fiber reinforced polyester. Composites Science and Technology. 2011; 62(1011):1433-1444. doi:10.1016/S0266-3538(02)00087-8.

7. Oskouei AR, Ahmadi M. Acoustic emission characteristics of mode I delamination in glass/polyester composites. Journal of Composite Materials. 2010; 44(7):793-807. doi: 10.1177/0021998309349553.

8. Berthelot JM, Rhazi J. Acoustic emission in carbon fibre composites. Composites Science and Technology. 1990; 37(4):411-428. doi:10.1016/0266-3538(90)90012-T.

9. Oskouei AR, Ahmadi M, Hajikhani M. Wavelet-based acoustic emission characterization of damage mechanisms in composite materials under mode I delamination at different interfaces. Express Polymer Letters. 2009; 3(12):804-813. doi: 10.3144/ expresspolymlett.2009.99.

10. Bascom WD: Fractography of Composite Delamination. NASA Contractor Report 181965; 1990.

11. Aggelis DG, Shiotani T, Papacharalampopoulos A, Polyzos D. The influence of propagation path on elastic waves as measured by acoustic emission parameters. Structural Health Monitoring. 2011; 11(3):359-366. doi: 10.1177/1475921711419992.

12. Chen F, Bazhenov S, Hiltner A, Baer E. Flexural failure mechanisms in unidirectional glass fibre reinforced thermoplastics. Composites. 1994; 25(1):11-20. doi:10.1016/0010-4361(94)90062-0.

13. Ireman T, Thesken JC, Greenhalgh E, Sharp R, Gädke M, Maison $S$, et al. Damage propagation in composite structural elementscoupon experiments and analyses. Composite Structures. 1996; 36(3-4):209-220. doi:10.1016/S0263-8223(96)00078-5.

14. Kempf M, Skrabala $O$, Altstädt V. Acoustic emission analysis for characterisation of damage mechanisms in fibre reinforced thermosetting polyurethane and epoxy. Composites Part B: Engineering. 2014; 56:477-483. doi:10.1016/j. compositesb.2013.08.080.

15. Unnthorsson R, Runarsson TP, Jonsson MT. Acoustic emission based fatigue failure criterion for CFRP. International Journal of Fatigue. 2008; 30(1):11-20. doi:10.1016/j.ijfatigue.2007.02.024.

16. Woo SC, Choi NS. Analysis of fracture process in single-edgenotched laminated composites based on the high amplitude acoustic emission events. Composites Science and Technology. 2007; 67(7-8):1451-1458. doi:10.1016/j.compscitech.2006.07.022.

17. Liu PF, Chu JK, Liu YL, Zheng JY. A study on the failure mechanisms of carbon fiber/epoxy composite laminates using acoustic emission. Materials and Design. 2012; 37:228-235. doi:10.1016/j. matdes.2011.12.015.

18. Ni QQ, Iwamoto M. Wavelet transform of acoustic emission signals in failure of model composites. Engineering Fracture Mechanics. 2002; 69(6):717-728. doi:10.1016/S0013-7944(01)00105-9.

19. Oskouei AR, Heidary H, Ahmadi M, Farajpur M. Unsupervised acoustic emission data clustering for the analysis of damage mechanisms in glass/polyester composites. Materials and Design. 2012; 37:416-422. doi:10.1016/j.matdes.2012.01.018. 
Citation: S Sajith, V Arumugam and C Santulli (2015) Failure Mode Discrimination in Mode II Fracture of Glass/Epoxy Laminates Using Acoustic Emission Technique. Mater. Sci. Eng. Adv. Res 1(2): 16-25. doi: https://doi.org/10.24218/msear.2015.09.

20. Kordatos EZ, Dassios KG, Aggelis DG, Matikas TE. Rapid evaluation of the fatigue limit in composites using infrared lock-in thermography and acoustic emission. Mechanics Research Communications. 2013; 54:13-20. doi:10.1016/j.mechrescom.2013.09.005.

21. Mechraoui SE, Laksimi A, Benmedakhene S. Reliability of damage mechanism localisation by acoustic emission on glass/epoxy composite material plate. Composite Structures. 2012; 94(5):14831494. doi:10.1016/j.compstruct.2011.11.037.

22. Arumugam V, Kumar B, Santulli C, Stanley AJ. Effect of fiber orientation in unidirectional glass epoxy laminate using acoustic emission monitoring. Acta Metallurgica Sinica (English Letters). 2011; 24(5):351-364
23. Santulli C. Matrix cracking detection by acoustic emission in polymer composites and counts/duration ratio. E-J Non Destructive Testing. 2012; 17(11).

24. Pereira AB, de Morais AB, Marques AT, de Castro PT. Mode II interlaminar fracture of carbon/epoxy multidirectional laminates. Composites Science and Technology. 2004; 64(10-11):1653-1659. doi:10.1016/j.compscitech.2003.12.001.

25. Chaplin CR. Compressive fracture in undirectional glass-reinforced plastics. Journal of Materials Science. 1977; 12(2):347-352. doi: 10.1007/BF00566277.

26. de Groot PJ, Wijnen PAM, Janssen RBF. Real-time frequency determination of acousticemissionfor differentfracturemechanisms in carbon/epoxy composites. Composites Science and Technology. 1995; 55(4):405-412. doi:10.1016/0266-3538(95)00121-2. 